\title{
Coercivity Enhancement of Hot-deformed Nd-Fe-B Magnets by the Eutectic Grain Boundary Diffusion Process
}

\author{
Lihua Liu $^{1,2)}$, H-Sepehri-Amin ${ }^{1)}$, T. Ohkubo ${ }^{1)}$, M. Yano ${ }^{3)}$, A. Kato ${ }^{3)}$, T. Shoji ${ }^{3)}$ and K. Hono ${ }^{1,2),{ }^{*}}$
}

1) Elements Strategy Initiative Center for Magnetic Materials, National Institute of Materials Science, Tsukuba 305-0047, Japan

2) Graduate School of Pure and Applied Science, University of Tsukuba, Tsukuba 305-8577, Japan

3) Toyota Motor Corporation, Advanced Material Engineering Div., Susono 410-1193, Japan

\begin{abstract}
Nd-M (M= Al, $\mathrm{Cu}, \mathrm{Ga}, \mathrm{Zn}, \mathrm{Mn})$ alloys with compositions close to eutectic points were investigated as diffusion sources for the grain boundary diffusion process to hot-deformed Nd-FeB magnets. Coercivity enhancement was observed for most of the alloys. Among them, the sample processed with $\mathrm{Nd}_{90} \mathrm{Al}_{10}$ exhibited the highest coercivity of $2.5 \mathrm{~T}$ at room temperature. However, the sample processed with $\mathrm{Nd}_{70} \mathrm{Cu}_{30}$ exhibited the highest coercivity of $0.7 \mathrm{~T}$ at $200{ }^{\circ} \mathrm{C}$. Microstructural observations using scanning transmission electron microscope (STEM) showed that nonferromagnetic Nd-rich intergranular phase envelops the $\mathrm{Nd}_{2} \mathrm{Fe}_{14} \mathrm{~B}$ grains after the diffusion process. Abnormal grain growth and the dissolution of $\mathrm{Al}$ into the $\mathrm{Nd}_{2} \mathrm{Fe}_{14} \mathrm{~B}$ grains were observed in the sample processed with $\mathrm{Nd}_{90} \mathrm{Al}_{10}$, which explains its inferior thermal stability of coercivity compared to the sample processed with $\mathrm{Nd}_{70} \mathrm{Cu}_{30}$. The coercivity enhancement and poor thermal stability of the coercivity of the $\mathrm{Nd}_{90} \mathrm{Al}_{10}$ diffusion-processed sample are discussed based on microstructure studies by transmission electron microscopy.
\end{abstract}

Keywords: Permanent magnets; Nd-Fe-B; Coercivity; Diffusion process; Grain boundary phase

\footnotetext{
*Corresponding author: kazuhiro.hono@nims.go.jp
} 


\section{Introduction}

The anisotropic Nd-Fe-B magnets produced by hot-pressing and subsequent hot-deformation of melt-spun isotropic nanocrystalline powder, known as hot-deformed magnets, are comprised of [001]-textured platelet-shaped $\mathrm{Nd}_{2} \mathrm{Fe}_{14} \mathrm{~B}$ grains of typically $\sim 100 \mathrm{~nm}$ in thickness and 300-400 in width $[1,2]$. The strong (001) texture develops during the hot-deformation or upsetting process $[3,4]$, which is considered to be due to the orientation dependent grain growth of tetragonal $\mathrm{Nd}_{2} \mathrm{Fe}_{14} \mathrm{~B}$ phase [4-7] or the anisotropy of its elastic properties [8]. Owing to the ultrafine grain size that is comparable to the single domain size, the hot-deformed magnets show relatively larger coercivity compared to sintered magnets. The remanent magnetization $\mu_{0} M_{\mathrm{r}}$ of $1.4 \mathrm{~T}$ reported for a hot-deformed magnet is comparable to that of commercial Nd-Fe-B sintered magnets $[9,10]$, indicating that the overall permanent magnetic properties of hot-deformed magnets are competitive with those of sintered magnets. Considering the fact that the average grain size is one order magnitude smaller than that of sintered magnets, the hot-deformed magnets should have potential for achieving higher coercivity at elevated temperature. DyF 3 and $\mathrm{DyCu}$ alloy additions to melt-spun $\mathrm{Nd}-\mathrm{Fe}-\mathrm{B}$ ribbons followed by hot-pressing and hotdeformation were found to be capable of improving coercivity by formation of the thin $(\mathrm{Nd}, \mathrm{Dy})_{2} \mathrm{Fe}_{14} \mathrm{~B}$ layer $[11,12]$. However, even with the Dy addition, the highest coercivity so far reported for the anisotropic hot-deformed magnets was limited to around $2.0 \mathrm{~T}$.

Lewis et al. [13-15] attributed this relatively low coercivity to the exchange coupling between $\mathrm{Nd}_{2} \mathrm{Fe}_{14} \mathrm{~B}$ grains through a ferromagnetic intergranular phase that contains high concentration of Fe and Co. They also pointed out that the intergranular phase does not form along the side surface of the platelet-shaped grains [16]. Based on more recent three-dimensional atom probe (3DAP) study, Liu et al. [10] have shown a clear correlation between the $\mathrm{Nd}$ concentration in the grain 
boundary phase and the coercivity of hot-deformed magnets, suggesting that the modification of the composition of the grain boundary phase may lead to substantial improvement in coercivity.

Sepehri-Amin et al. [17] reported the coercivity of hydrogen-disproportionationdecomposition-recombination processed Nd-Fe-B magnet powder can be largely enhanced by infiltrating a low melting temperature $\mathrm{Nd}_{70} \mathrm{Cu}_{30}$ eutectic alloy. Thereafter, they applied this eutectic grain boundary diffusion process to hot-deformed magnets and demonstrated that the coercivity is enhanced from $1.4 \mathrm{~T}$ to $2.3 \mathrm{~T}$ using the $1 \mathrm{~mm}$ thick hot-deformed Nd-Fe-B magnets [18]. They have also shown that this enhancement of coercivity mainly stems from the enrichment of $\mathrm{Nd}$ in the intergranular phases by the infiltration of $\mathrm{Nd}-\mathrm{Cu}$ liquid through grain boundaries. This method was later extended to bulk hot-deformed magnets and a balanced combination of coercivity $(1.9 \mathrm{~T})$ and remanence $(1.35 \mathrm{~T})$ was attained using the expansion constraint eutectic diffusion process [19]. However, a higher level of coercivity of $2.5 \mathrm{~T}$ is required for automotive traction motor applications.

Neodymium has eutectic reactions with various types of $\mathrm{Nd}_{x} \mathrm{M}_{y}$ compounds, where $\mathrm{M}$ includes $\mathrm{Al}, \mathrm{Cu}, \mathrm{Ga}, \mathrm{Zn}, \mathrm{Mn}, \mathrm{Co}, \mathrm{Ni}$ and $\mathrm{Fe}$. However, only a few eutectic systems, $\mathrm{Nd}-\mathrm{Cu}$ and $\operatorname{Pr}-\mathrm{Cu}$, were explored for the eutectic grain boundary diffusion process $[18,20]$. Previous studies $[21,22]$ suggested that the addition of $\mathrm{Al}$ and $\mathrm{Ga}$ improve the wettability between $\mathrm{Nd}_{2} \mathrm{Fe}_{14} \mathrm{~B}$ and intergranular phases, which may smoothen the intergranular phase for better separation of $\mathrm{Nd}_{2} \mathrm{Fe}_{14} \mathrm{~B}$ grains. With partial substitution of $\mathrm{Al}$ for $\mathrm{Fe}$ [23], $\mathrm{Nd}_{2} \mathrm{Fe}_{14-x} \mathrm{Al}_{x} \mathrm{~B}$ compounds are known to exhibit higher anisotropy field accompanied by the reduction in magnetization.

In order to explore which alloy system will give the highest coercivity among various Nd-M systems, we employed various eutectic alloys as the diffusion source for the grain boundary diffusion process to hot-deformed Nd-Fe-B magnets. The mechanism of the coercivity 
enhancement of hot-deformed magnets is discussed on the basis of detailed microstructure characterizations by scanning electron microscopy (SEM) and transmission electron microscopy (TEM).

\section{Experimental}

Hot-deformed magnets in $4 \times 4 \times 2 \mathrm{~mm}^{3}$ size with the composition of $\mathrm{Nd}_{13.2} \mathrm{Fe}_{76} \mathrm{Co}_{5.6} \mathrm{~B}_{4.7} \mathrm{Ga} 0.5$ (at.\%) upset processed at $780^{\circ} \mathrm{C}$ were used as starting samples. Flakes of the Nd-rich eutectic alloys, $\mathrm{Nd}_{90} \mathrm{Al}_{10}, \mathrm{Nd}_{82} \mathrm{Al}_{18}, \mathrm{Nd}_{80} \mathrm{Ga}_{20}, \mathrm{Nd}_{70} \mathrm{Cu}_{30}, \mathrm{Nd}_{75} \mathrm{Zn}_{25}, \mathrm{Nd}_{50} \mathrm{Pr}_{20} \mathrm{Cu}_{30}$ and $\mathrm{Nd}_{60} \mathrm{Al}_{30} \mathrm{Cu}_{10}$ were fabricated with a single-roller melt-spinning machine. The diffusion process was carried out by wrapping the hot-deformed magnets with eutectic alloy ribbons in $\mathrm{Nb}$ foil, annealing at various temperatures for $1 \mathrm{~h}$. The annealing temperature was chosen based on the melting temperature of the diffusion sources. In order to investigate the upper limit of the coercivity enhancement through the diffusion process, no control of the amount of the infiltration was made in this work, i.e., no consideration was made for the loss of remanence.

Magnetic measurements of the hot-deformed magnet and the diffusion-processed magnets were carried out in a superconducting quantum interface device vibrating sample magnetometer (SQUID-VSM) for the specimen sliced crossing sample surface and center. Correction of demagnetization field was made using the equation of $H_{\mathrm{eff}}=H_{\mathrm{ext}}-N_{\mathrm{d}} M$, where $H_{\text {eff }}$ denotes as effective field, $H_{\text {ext }}$ refers to external field, while $N_{\mathrm{d}}$ is the demagnetization factor which was calculated for the prism specimen configuration described in ref[24]. Overall microstructural characterization was conducted using Carl ZEISS CrossBeam 1540EsB and surfaces of samples were cleaned using Focused Ion Beam (FIB) before SEM observation. Scanning transmission electron microscopy energy-dispersive spectroscopy (STEM EDS) maps were constructed using 
$\mathrm{Nd}-L_{\alpha}, \mathrm{Dy}-M_{\alpha}, \mathrm{Fe}-K_{\alpha}, \mathrm{Co}-K_{\alpha}$ and $\mathrm{Cu}-K_{\alpha}$ spectrum. The TEM specimens were prepared with the lift-out method using a focused ion beam on FEI Nanolab Helios 650.

\section{Results}

Fig. 1(a) shows the demagnetization curves of the initial hot-deformed magnet and the ones diffusion-processed using various diffusion sources. Large enhancement of coercivity $\left(\mu_{0} H_{\mathrm{c}}\right)$ was realized by the diffusion process using $\mathrm{Nd}_{90} \mathrm{Al}_{10}, \mathrm{Nd}_{82} \mathrm{Al}_{18}, \mathrm{Nd}_{80} \mathrm{Ga}_{20}, \mathrm{Nd}_{70} \mathrm{Cu}_{30}, \mathrm{Nd}_{75} \mathrm{Zn}_{25}$, $\mathrm{Nd}_{50} \mathrm{Pr}_{20} \mathrm{Cu}_{30}$ and $\mathrm{Nd}_{60} \mathrm{Al}_{30} \mathrm{Cu}_{10}$ alloys as the diffusion sources. Degradation of coercivity was observed when the diffusion process was applied at $750^{\circ} \mathrm{C}$ for $\mathrm{Nd}_{75} \mathrm{Mn}_{25}$ and $\mathrm{Nd}_{82} \mathrm{Al}_{18}$ because of grain coarsening. Remanence $\left(\mu_{0} M_{\mathrm{r}}\right)$ of the diffusion-processed samples decreased as a result of the infiltration of the diffusion sources into the magnet.

Fig. 1(b) summarizes the remanence and the coercivity of the diffusion-processed samples, indicating the infiltration of $\mathrm{Nd}_{90} \mathrm{Al}_{10}$ is the most effective in enhancing the coercivity. After the diffusion process at $700^{\circ} \mathrm{C}$ for $1 \mathrm{~h}$ using $\mathrm{Nd}_{90} \mathrm{Al}_{10}$, coercivity increased from $1.3 \mathrm{~T}$ to $2.5 \mathrm{~T}$, with the remanence decreases from $1.51 \mathrm{~T}$ to $1.21 \mathrm{~T}$. Using $\mathrm{Nd}_{70} \mathrm{Cu}_{30}$ as a diffusion source, $\mu_{0} H_{\mathrm{c}}$ of 2.3 $\mathrm{T}$ was obtained at a relatively low diffusion process temperature of $600^{\circ} \mathrm{C}$. This low processing temperature for $\mathrm{Nd}_{70} \mathrm{Cu}_{30}$ compared to other alloys is due to the low $\mathrm{Nd} / \mathrm{NdCu}$ eutectic temperature of $520^{\circ} \mathrm{C}$.

Fig. 2(a) presents the temperature dependence of the coercivities of the samples diffusionprocessed with $\mathrm{Nd}_{90} \mathrm{Al}_{10}$ and $\mathrm{Nd}_{70} \mathrm{Cu}_{30}$. The $\mathrm{Nd}_{90} \mathrm{Al}_{10}$ diffusion-processed sample exhibits faster degradation in coercivity with increasing temperature compared to that of $\mathrm{Nd}_{70} \mathrm{Cu}_{30}$ diffusionprocessed sample; as a result, $\mathrm{Nd}_{90} \mathrm{Al}_{10}$ diffusion-processed sample possesses lower coercivity of 
$0.6 \mathrm{~T}$ than that of the $\mathrm{Nd}_{70} \mathrm{Cu}_{30}$ diffusion-processed sample, $0.7 \mathrm{~T}$, at $200^{\circ} \mathrm{C}$. Figure 2 (b) shows $H_{\mathrm{c}}(T) / M_{\mathrm{s}}(T)$ plotted as functions of $H_{\mathrm{a}}(T) / M_{\mathrm{s}}(T)$, where $H_{\mathrm{c}}(T)$ is experimentally measured temperature dependent coercivity, and $M_{\mathrm{s}}(T)$ and $H_{\mathrm{a}}(T)$ are the temperature dependent magnetization and anisotropy field for $\mathrm{Nd}_{2} \mathrm{Fe}_{14} \mathrm{~B}$ taken from ref [25]. $H_{\mathrm{c}}(\mathrm{T}) / M_{\mathrm{s}}(\mathrm{T})$ shows a near linear correlation against $H_{\mathrm{A}}(\mathrm{T}) / M_{\mathrm{s}}(\mathrm{T})$ with $\alpha$ as the slope, $N_{\text {eff }}$ as the intercept of the phenomenological micromagnetic equation, $H_{\mathrm{c}}(\mathrm{T})=\alpha H_{A}(\mathrm{~T})-N_{\mathrm{eff}} M_{\mathrm{s}}(\mathrm{T})$. In this model, $\alpha$ reflects decreased anisotropy field induced by the defect regions at grain boundaries as well as grain

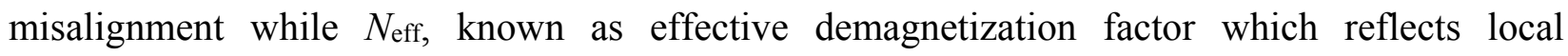
demagnetizing filed [25]. By linear fit of $H_{\mathrm{c}} / M_{\mathrm{s}}$ vs. $H_{\mathrm{A}} / M_{\mathrm{s}}$ plot, $\alpha$ values derived for $\mathrm{Nd}_{90} \mathrm{Al}_{10}$ and $\mathrm{Nd}_{70} \mathrm{Cu}_{30}$ diffusion processed samples are 0.79 and 0.61 , respectively, substantially increased from 0.34 of the hot-deformed magnet. However, $N_{\text {eff }}$ values increase from 0.79 to 1.47 and 0.94 for $\mathrm{Nd}_{90} \mathrm{Al}_{10}$ and $\mathrm{Nd}_{70} \mathrm{Cu}_{30}$ diffusion-processed samples, respectively. The larger $N_{\mathrm{eff}}$ for the $\mathrm{Nd}_{90} \mathrm{Al}_{10}$ diffusion processed sample is due the larger grain size because the processing temperature for $\mathrm{Nd}_{90} \mathrm{Al}_{10}$ is $100^{\circ} \mathrm{C}$ higher than that for $\mathrm{Nd}_{70} \mathrm{Cu}_{30}$.

Fig. 3(a) and (b) show the backscattered electron (BSE) SEM images of the hot-deformed and $\mathrm{Nd}_{90} \mathrm{Al}_{10}$ diffusion-processed samples, respectively, taken from the side cross-sections of the samples (c-axis in-plane upward), while Fig. 3(d) and (e) are the images observed from the top surface of the samples (c-axis out-of-plane). The average grain size of the hot-deformed magnet is $\sim 282 \pm 94 \mathrm{~nm}$ in width and $\sim 72 \pm 22 \mathrm{~nm}$ in thickness. The grain size increased to $\sim 299 \pm 138$ and $\sim 100 \pm 66 \mathrm{~nm}$ respectively for the $\mathrm{Nd}_{90} \mathrm{Al}_{10}$ diffusion-processed sample. The average grain size of the $\mathrm{Nd}_{90} \mathrm{Al}_{10}$ diffusion-processed sample is comparable to that of the initial hot-deformed magnet. However, the large standard deviation of $\mathrm{Nd}_{90} \mathrm{Al}_{10}$ infiltrated sample implies a much 
larger distribution in the grain size, which is caused by the high annealing temperature for the $\mathrm{Nd}_{90} \mathrm{Al}_{10}$ diffusion-process. Such abnormally grown grains in the $\mathrm{Nd}_{90} \mathrm{Al}_{10}$ diffusion-processed sample (indicated by the red arrows in Fig.3b and d) have not been observed in the $\mathrm{Nd}_{70} \mathrm{Cu}_{30}$ diffusion-processed sample [18]. These images also show good isolation of $\mathrm{Nd}_{2} \mathrm{Fe}_{14} \mathrm{~B}$ grains by the intergranular Nd-rich phase, which forms not only along the c-plane but also at the side grain boundaries. In comparison, the $\mathrm{Nd}_{2} \mathrm{Fe}_{14} \mathrm{~B}$ grains of the hot-deformed magnets are mostly in contact with each other in both parallel and perpendicular directions to the platelets. The areal fractions of the Nd-rich phase increased from $5 \%$ of the hot-deformed magnet to $27 \%$ of $\mathrm{Nd}_{90} \mathrm{Al}_{10}$ infiltrated sample. With this large volume fraction of Nd-rich intergranular phase, the $\mathrm{Nd}_{2} \mathrm{Fe}_{14} \mathrm{~B}$ grains are expected to be magnetically isolated. Note that two types of contrasts are observed in the intergranular phase; one with a relatively bright contrast and the other has a dim contrast, suggesting non-uniform distributions of $\mathrm{Co}$ and $\mathrm{Ga}$ in the Nd-rich intergranular phase, the details of which will be described later.

Bright field (BF) transmission microscopy (TEM) and Lorentz TEM images of the hotdeformed and $\mathrm{Nd}_{90} \mathrm{Al}_{10}$ diffusion-processed samples are shown in Fig. 4. Large amount of wavypatterned strain-induced fringes are observed in the $\mathrm{Nd}_{90} \mathrm{Al}_{10}$ diffusion-processed sample (Fig. $4 b)$, which are not evident in the initial hot-deformed sample. This is believed to originate from the lattice mismatch between the main phase and the crystalline Nd-rich intergranular phase. The over-focused Lorentz-TEM images show domain walls in bright and dark contrasts. The domain wall appears to be continuous across the grain boundaries parallel to the broad surface of the platelet-like grains in the initial hot-deformed sample (Fig. 4c). On the other hand, the domain walls are interrupted in the intergranular phase in the $\mathrm{Nd}_{90} \mathrm{Al}_{10}$ diffusion-processed sample (Fig.4d), suggesting the grain boundary phase is non-ferromagnetic after the diffusion process. In 
spite of the exchange decoupling of the grains, the domain walls lie linearly because of the magnetostatic interaction among the grains.

STEM-EDS maps of the hot-deformed and $\mathrm{Nd}_{90} \mathrm{Al}_{10}$ diffusion-processed samples are shown in Fig. 5(a) and (b), respectively, with c-axis in-plane. In the initial hot-deformed sample, Nd-rich intergranular phase is not clearly visible. In most cases, $\mathrm{Nd}_{2} \mathrm{Fe}_{14} \mathrm{~B}$ grains are in direct contact with each other; Co shows uniform distribution while Ga appears to be enriched in the intergranular phase. In the $\mathrm{Nd}_{90} \mathrm{Al}_{10}$ diffusion processed sample, Fig. 5(b), thick Nd-rich intergranular phase forms parallel to the flat surface of the platelet-shaped $\mathrm{Nd}_{2} \mathrm{Fe}_{14} \mathrm{~B}$ grains. Thinner $\mathrm{Nd}-$ rich intergranular phase is observed at the side boundaries; however, many platelet grains appear to be interconnected in the longitudinal direction. Two types of contrasts are observed in the Co, Ga and Al maps, indicating the Nd-rich intergranular phase is separated into two phases, i.e., $(\mathrm{Nd}, \mathrm{Co})$-rich and $\mathrm{Nd}(\mathrm{Ga}, \mathrm{Al})$-rich phases.

The chemical composition and the crystal structure of these two different types of Nd-rich phases were examined by localized STEM-EDS quantification and nanobeam electron diffraction (NBED). Fig. 6(a) shows a superimposed elemental map of $\mathrm{Nd}$ and $\mathrm{Co}$ for visualizing the distribution of the (Nd,Co)-rich phase. The diffraction pattern shown in Fig. 6(b) is taken from the $\mathrm{Nd}_{2} \mathrm{Fe}_{14} \mathrm{~B}$ grain in the [100] zone axis. Fig. 6(d) shows the NBED pattern taken from the Ndrich phase, which can be indexed as an $f c c$ structure in the [013] zone axis. The lattice constant of this type of Nd-rich phase was calculated to be $\sim 0.54 \mathrm{~nm}$, which is consistent with the fcc Nd-rich phase reported in sintered Nd-Fe-B magnets [26,27]. From the NBED pattern taken from the interface region of $\mathrm{Nd}_{2} \mathrm{Fe}_{14} \mathrm{~B}$ phase and the Nd-rich intergranular region, the crystallographic orientation relationship $(\mathrm{OR})$ can be identified to be $[100]_{N d_{2} F e 14 B} / /[013]_{f c c-N d}$, 
$(0 \overline{4} 6)_{N_{2} F e 14 B} / /(1 \overline{3} 1)_{f c c-N d}$. The localized EDS quantification suggests that the composition of the $\mathrm{Nd}$-rich intergranular phase is $\sim \mathrm{Nd}_{79} \mathrm{Co}_{14} \mathrm{Fe}_{6} \mathrm{Al}_{1}$ (at.\%).

The chemical composition of $\mathrm{Nd}(\mathrm{Ga}, \mathrm{Al})$-rich regions shown in Fig. 7(a) shows the chemical composition is about $\sim \mathrm{Nd}_{62} \mathrm{Co}_{2} \mathrm{Fe}_{8} \mathrm{Al}_{8}$ (at.\%) with the amorphous structure (Fig. 7b). A layered contrast is seen in the HAADF-STEM image (Fig.7d), which comes from the periodical atomic layer stacking of the newly-formed phase, which has the composition of close to $\mathrm{Nd}(\mathrm{Fe}, \mathrm{Al})_{2}$ and the diffraction pattern of this phase is shown in Fig. 7(b). The lattice fringe shows a periodicity of $1.2 \mathrm{~nm}$ and calculated d-spacings are $3.4 \mathrm{~nm}$ and $4.2 \mathrm{~nm}$, respectively. Fidler et al. [28-30] referred this phase as al2 or $\delta$ phase that was first found in $\mathrm{Al}_{2} \mathrm{O}_{3}$-doped sintered magnets and they pointed out that this phase has a complex tetragonal structure. They also suggested that the al2 phase has a large anisotropy field and good wettability with $\mathrm{Nd}_{2} \mathrm{Fe}_{14} \mathrm{~B}$ grains, which was attributed to the high coercivity of $\mathrm{Al}$-doped or $\mathrm{Al}_{2} \mathrm{O}_{3}$-doped sintered magnets.

Fig. 8 shows the configuration of the Nd-rich intergranular phase in the direction perpendicular to the flat surface of the $\mathrm{Nd}_{2} \mathrm{Fe}_{14} \mathrm{~B}$ grains. The selected peaks for the elemental maps are $\mathrm{Nd} L_{\alpha}, \mathrm{Fe} K_{\alpha}, \mathrm{Co} K_{\alpha}, \mathrm{Ga} K_{\alpha}$ and $\mathrm{Al} K_{\alpha}$. Al is segregated at the interface between the intergranular phase and the $\mathrm{Nd}_{2} \mathrm{Fe}_{14} \mathrm{~B}$ phase. Line-scan analysis shows around 7.5 at. $\%$ of is segregated at the Nd-rich intergranular phase $/ \mathrm{Nd}_{2} \mathrm{Fe}_{14} \mathrm{~B}$ grain interface and about 3 at. $\%$ of $\mathrm{Al}$ was detected within the $\mathrm{Nd}_{2} \mathrm{Fe}_{14} \mathrm{~B}$ phase. The Nd-rich intergranular phase in the direction perpendicular to the flat surface of the platelet contains $\mathrm{Nd}$ close to 80 at. $\%$ with less than 10 at.\% Fe, suggesting the intergranular region is non-ferromagnetic. 


\section{Discussion}

This work has shown that the coercivity of hot-deformed magnets can be substantially enhanced by the grain boundary diffusion process using various RE-TM eutectic alloys as diffusion sources. Note that the coercivity of hot-deformed magnets is degraded if the diffusionprocess is applied above the temperature for the hot-deformation process. In fact, the hotdeformed magnets processed at $750^{\circ} \mathrm{C}$ using $\mathrm{Nd}_{75} \mathrm{Mn}_{25}$ and $\mathrm{Nd}_{82} \mathrm{Al}_{18}$ alloys did not show any improvement in coercivity because of abnormal grain growth at this high processing temperature.

The enhancement of the coercivity is mainly attributed to the exchange decoupling of the $\mathrm{Nd}_{2} \mathrm{Fe}_{14} \mathrm{~B}$ grains as a result of the formation of $\mathrm{Nd}$-rich intergranular phase by the infiltration of eutectic melts. This is evidenced from the microstructural characterizations by SEM and TEM. The concentration of $\mathrm{Fe}$ in the intergranular phase is much decreased after the diffusion process, indicating that the ferromagnetism in the grain boundary phase is diluted by the infiltration of the RE-TM eutectic alloy. Nearly complete magnetic isolation has been realized by the diffusion process when $\mathrm{Nd}_{90} \mathrm{Al}_{10}$ alloy is used as the diffusion source. The micromagnetic parameters $\alpha$ in $H_{\mathrm{c}}(\mathrm{T})=\alpha H_{A}(\mathrm{~T})-N_{\mathrm{eff}} M_{\mathrm{s}}(\mathrm{T})$ was improved for $\mathrm{Nd}{ }_{90} \mathrm{Al}_{10}$ and $\mathrm{Nd}_{70} \mathrm{Cu}_{30}$ diffusion-processed samples. Improved $\alpha$ suggests that the defect density at the interface that cause reduction of anisotropy field is reduced by diffusion of $\mathrm{Nd}-\mathrm{Cu}$ and $\mathrm{Nd}-\mathrm{Al}$ alloys. The $\mathrm{Nd}_{90} \mathrm{Al}_{10}$ diffusion processed sample has a slightly larger $\alpha$ value than that of $\mathrm{Nd}_{70} \mathrm{Cu}_{30}$ diffusion processed sample. This can originate from segregation of $\mathrm{Al}$ at the interface of $\mathrm{Nd}$-rich phases $/ \mathrm{Nd}_{2} \mathrm{Fe} 14 \mathrm{~B}$ grains as shown in Fig. 8 that may recover the reduced local anisotropy field at the surface of $\mathrm{Nd}_{2} \mathrm{Fe}_{14} \mathrm{~B}$ grains. Also, the $\mathrm{Al}$ substitution for $\mathrm{Fe}$ atoms is expected to increase anisotropy field of the $\mathrm{Nd}_{2} \mathrm{Fe}_{14} \mathrm{~B}$ phase 
[23]. The formation of the al2 phase in the grain boundary may also have a similar effect. These factors could contribute to the high coercivity of $\mathrm{Nd}_{90} \mathrm{Al}_{10}$ infiltrated sample at room temperature.

The larger $N_{\text {eff }}$ value of $\mathrm{Nd}_{90} \mathrm{Al}_{10}$ infiltrated sample is considered to be due to the dispersed grain size distribution after the high processing temperature required for the $\mathrm{Nd}_{90} \mathrm{Al}_{10}$ infiltration. Non-uniform grain size distribution leads to poorer thermal stability as a result of the nonuniform nucleation of reversed magnetic domains due to the larger stray field from those abnormally grown grains [31]. In addition, enrichment of 3 at.\% $\mathrm{Al}$ in the $\mathrm{Nd}_{2} \mathrm{Fe}_{14} \mathrm{~B}$ phase can reduces the Curie temperature of $\mathrm{Nd}_{2} \mathrm{Fe}_{14} \mathrm{~B}$ phase which can be an additional reason for the poorer thermal stability of coercivity in $\mathrm{Nd}_{90} \mathrm{Al}{ }_{10}$ diffusion-processed sample compared with that of $\mathrm{Nd}_{70} \mathrm{Cu}_{30}$ diffusion-processed sample.

The coercivity of $\mathrm{Nd}_{70} \mathrm{Cu}_{30}$ diffusion-processed sample at $200^{\circ} \mathrm{C}$ (typical operation temperature of traction motors of hybrid vehicles) is $0.7 \mathrm{~T}$, which is close to $0.8 \mathrm{~T}$ of the currently used ( $\mathrm{Nd}{ }_{0.7 \mathrm{Dy}} \mathrm{D}_{\text {.3) }}$-Fe-B sintered magnets. With the development of cooling technique in traction motors, the application of the $\mathrm{Nd}-\mathrm{Cu}$ diffusion-processed magnets may become practical in the near future.

The remaining issue of the eutectic diffusion process is the optimization of the thickness of the intergranular phase, especially those located parallel to the broad surface of the plateletshaped $\mathrm{Nd}_{2} \mathrm{Fe}_{14} \mathrm{~B}$ grains. As seen in Fig. 1, large coercivity enhancement was achieved at the expense of remanence because of the large volume fraction of non-ferromagnetic intergranular phase. In order to keep the remanence high, a smaller amount of diffusion source should be infiltrated. For this purpose, the usage of diffusion sources with higher diffusivity with lower melting-point may be effective. The diffusion process using lower melting temperature alloys will also be beneficial in optimizing the grain size distribution of the diffusion-processed magnets 
since grain coarsening during the eutectic diffusion process is detrimental for the thermal stability of the hot-deformed magnets.

\section{Conclusion}

Coercivity improvement has been realized for hot-deformed Nd-Fe-B magnets using Nd-Al, $\mathrm{Nd}-\mathrm{Cu}, \mathrm{Nd}-\mathrm{Zn}, \mathrm{Nd}-\mathrm{Ga}, \mathrm{Nd}-\mathrm{Cu}-\mathrm{Al}$ and $\mathrm{Nd}-\mathrm{Pr}-\mathrm{Cu}$ eutectic alloys as diffusion sources. At room temperature, the sample diffusion processed at $700^{\circ} \mathrm{C}$ using $\mathrm{Nd}_{90} \mathrm{Al}_{10}$ shows the highest coercivity of $2.5 \mathrm{~T}$. However, it exhibits pronounced degradation of coercivity with increasing temperature compared to the sample diffusion-processed with $\mathrm{Nd}_{70} \mathrm{Cu} 30$. Thus, at $200^{\circ} \mathrm{C}, \mathrm{Nd}_{70} \mathrm{Cu} 30$ diffusionprocessed sample possesses the highest coercivity of $0.7 \mathrm{~T}$, indicating that $\mathrm{Nd}-\mathrm{Cu}$ alloy is still the most promising diffusion source for the eutectic grain boundary diffusion process.

Co-enriched Nd-rich phase was determined to be an $f c c$ phase which has a good crystallographic match with the $\mathrm{Nd}_{2} \mathrm{Fe}_{14} \mathrm{~B}$ phase. An Al-containing phase (al2) was observed in the $\mathrm{Nd}_{90} \mathrm{Al}_{10}$ diffusion-processed sample with the composition of $\mathrm{Nd}(\mathrm{Fe}, \mathrm{Al})_{2}$ and a tetragonal structure.

\section{Acknowledgement}

This work was in part supported by JST, CREST and MagHEM. Lihua Liu acknowledges NIMS for the provision of the NIMS Junior Research Assistantship. 


\section{References}

[1] R. W. Lee, Hot-pressed neodymium-iron-boron magnets, Appl. Phys. Lett. 49 (1985) 790-791.

[2] R. K. Mishra, T. Y. Chu, L. K. Rabenberg, The development of the microstructure of die-upset Nd-FeB magnets, J. Magn. Magn. Mater. 84 (1990) 88-94.

[3] W. Grünberger, D. Hinz, A. Kirchner, K.-H. Müller, L. Schultz, Hot deformation of nanocrystalline Nd-Fe-B alloys, IEEE Trans. Magn. 33 (1997) 3889-3891.

[4] R. W. Lee, E. G. Brewer, N. A. Schaffel, Processing of neodymium-iron-boron melt-spun ribbons to fully dense magnets, IEEE Trans. Magn. MAG-21,(1985) 1958-1963.

[5] R. K. Mishra, R. W. Lee, Microstructure, domain walls, and magnetization reversal in hot-pressed NdFe-B magnets, Appl. Phys. Lett. 48 (1986) 733-735.

[6] P. Tenaud, A. Chamberod, F. Vanoni, Texture in Nd-Fe-B magnets analysed on the basis of the determination of $\mathrm{Nd}_{2} \mathrm{Fe}_{14} \mathrm{~B}$ single crystals easy growth axis, Solid State Commun. 63 (1987) 303-305.

[7] M. Leonowicz, H. A. Davies, Effect of Nd content on induced anisotropy in hot deformed Fe-Nd-B magnets, Mat. Lett. 19 (1994) 275-279.

[8] L. Li, D. E. Luzzi, C. D. Graham, High-resolution electron microscope study of the grain boundary phase in rapidly quenched Nd-Fe-B permanent magnet alloys, J. Matter. Eng. Perform. 1 (1992) 205209.

[9] W. F. Li, T. Ohkubo, K. Hono, Effect of post-sinter annealing on the coercivity and microstructure of Nd-Fe-B permanent magnets, Acta Mater. 57 (2009) 1337-1346.

[10] J. Liu, H. Sepehri-Amin, T. Ohkubo, K. Hioki, A. Hattori, T. Schrefl, K. Hono, Effect of Nd content on the microstructure and coercivity of hot-deformed Nd-Fe-B permanent magnets, Acta Mater. 51 (2013) 5387-5399. 
[11] S. Sawatzki, I. Dirba, H. wendrock, L. Schultz, O. Gutfleisch, Diffusion processes in hot-deformed Nd-Fe-B magnets with $\mathrm{DyF}_{3}$ additions, J. Magn. Magn. Mat. 358-359 (2014) 163-169.

[12] N. Watanabe, M. Itakura, M. Nishida, Microstructure of high coercivity Nd-Fe-Co-Ga-B hotdeformed magnet improved by the Dy diffusion treatment, J. Alloy. Compd. 557 (2013) 1-4.

[13] L. H. Lewis, Y. Zhu, D. O. Welch, Evidence for reversal by nucleation in RE-Fe-B die-upset magnets, J. Appl. Phys. 76 (1994) 6235-6237.

[14] L. H. Lewis, Y. M. Zhu, D. O. Welch, Ferromagnetic grain boundary signature in die-upset RE-Fe-B magnets, Scipta Metall. Mater. 33 (1995) 1775-1780.

[15] T. D. Nguyen, K. M. Krishnan, L. H. Lewis, Y. Zhu, D. O. Welch, Microstructure and composition in rapidly quenched Nd-Fe-B hard magnet alloys, J. Appl. Phys. 79 (1996) 4848-4850.

[16] L. H. Lewis, T. R. Thurston, V. Panchanathan, U. Wildgruber, D. O. Welch, Spatial texture distribution in thermodynamically deformed 2-14-1-based magnets, J. Appl. Phys. 82 (1997) 34303441.

[17] H. Sepehri-Amin, T. Ohkubo, T. Nishiuchi, S. Hirosawa, K. Hono, Coercivity emhancement of hydrogenation-disproportionation-desorption-recombination processed $\mathrm{Nd}-\mathrm{Fe}-\mathrm{B}$ powders by the diffusion of Nd-Cu eutectic alloys, Scripta Mater. 63 (2010) 1124-1127.

[18] H. Sepehri-Amin, T. Ohkubo, S. Nagashima, M. Yano, T. Shoji, A. Kato, T. Schrefl, K. Hono, Highcoercivity ultrafine-grained anisotropic Nd-Fe-B magnets processed by hot deformation and the Nd$\mathrm{Cu}$ grain boundary diffusion process, Acta Mater. 61 (2013) 6622-6634.

[19] T. Akiya, J. Liu, H. Sepehri-Amin, T. Ohkubo, K. Hioki, A. Hattori, K. Hono, High-coercivity hotdeformed $\mathrm{Nd}-\mathrm{FeB}$ permanent magnets processed by $\mathrm{Nd}-\mathrm{Cu}$ eutectic diffusion under expansion constraint, Scripta Mater. 81 (2014) 48-51.

[20] H.Sepehri-Amin, Lihua Liu, T. Ohkubo, M. Yano, T. Shoji, A. Kato, T. Schrefl, K. Hono, Microstructure and temperature dependent of coerciivty of hot-deformed Nd-Fe-B magnets diffusion processed with Pr-Cu alloy, Acta Mater. 99 (2015) 297-306. 
[21] K. G. Knoch, B. Grieb, E.-Th. Henig, H. Kronmüller, G. Petzow, Upgraded Nd-Fe-B-AD (AD = Al, Ga) magnets: wettability and microstructure, IEEE Trans. Magn. 26 (1990) 1951-1953.

[22] K. G. Knoch, E.-Th. Henig, J. Fidler, Correlation between Al addition and microstructural changes in Nd-Fe-B magnets, J. Magn. Magn. Mater. 83 (1990) 209-210.

[23] W. Rodewald, W. Fernengel, Properties of sintered Nd-Fe-B magnets, IEEE Trans. Magn. 24 (1988) 1638-1643.

[24] A. Aharoni, Demagnetization factors for rectangular ferromagnetic prisms, J. Appl. Phys. 83 (1998) $3432-3434$

[25] H. Kronmüller, R. Fischer, M. Seeger, A. Zern, Mciromagnetism and microstructure of hard magnetic materials, J. Phys. D: Appl. Phys. 29 (1996) 2274-2283.

[26]Y. Shinba, T. J. Konno, K. Ishikawa, K. Hiraga, M. Sagawa, Transmission electron microscopy study on Nd-rich phase and grain boundary structure of Nd-Fe-B sintered magnets, J. Appl. Phys. 97 (2005) 053504.

[27] Q. Liu, F. Xu, J. Wang, X. Dong, L. Zhang, J. Yang, An investigation of the microstructure in the grain boundary region of Nd-Fe-b sintered magnet during post-sintering annealing, Scripta Mater. 68 (2013) 687-690.

[28] B. Grieb, E.-Th. Henig, G. Martinek, H. H. Stadelmaier, G. Petzow, Phase relations and magnetic properties of new phases in the Fe-Nd-Al and Fe-Nd-C systems and their influence on magnets, IEEE Trans. Magn. 26 (1990) 1367-1369.

[29] J. Fidler, K. G. Knoch, H. Kronmüller, G. Schneider, Analytical TEM study of Al-doped, "two-phase" Nd-Fe-B sintered magnets, J. Mater. Res. 4 (1989) 806-814.

[30] B. Grieb, K. G. Knoch, E. -Th. Henig, G. Petzow, Influence of Al-based additions on coercivity and microstructure in Fe-Nd-B magnets, J. Magn. Magn. Mater. 80 (1989) 75-79. 
[31] H. Sepehri-Amin, T. Ohkubo, M. Gruber, T. Schrefl, K. Hono, Micromagnetic simulations on the grain size dependence of coercivity in anisotropic Nd-Fe-B sintered magnets, Scripta Mater. 89 (2014) 29-32.

Fig. 1. (a) Demagnetization curves of the hot-deformed and diffusion-processed samples by various eutectic alloys, (b) remanence vs. coercivity plot of the hot-deformed and the diffusion-processed samples.

Fig. 2. (a) Temperature dependence of coercivity of the hot-deformed, Nd-Al and Nd-Cu diffusionprocessed samples, (b) dependence of $H_{\mathrm{c}} / M_{\mathrm{s}}$ on $H_{\mathrm{a}} / M_{\mathrm{s}}$ of the hot-deformed, Nd-Al and Nd-Cu diffusionprocessed samples. Micromagnetic parameters $\alpha$ and $N_{\text {eff }}$ are calculated from the slope and intercept of the linear fie line of these plots, respectively.

Fig. 3. BSE-SEM images of the hot-deformed $(a, c)$ and the NdAl-infiltrated (b,d) samples. The observation direction is in-plane $(a, b)$ and out-of-plane in $(c, d)$.

Fig. 4. BSE-SEM images of the hot-deformed $(a, c)$ and the NdAl-infiltrated $(b, d)$ samples. The observation direction is along c-axis in-plane $(a, b)$ and out-of-plane in $(c, d)$.

Fig. 5. TEM-EDS elemental mapping images of the hot-deformed (a) and the NdAl-infiltrated (b) samples with c-axis in-plane upward. The selected analysis peaks for the elemental maps are $\mathrm{Nd} L_{\alpha}, \mathrm{Fe} K_{\alpha}, \mathrm{Co} K_{\alpha}$, $\mathrm{Ga} K_{\alpha}$ and $\mathrm{Al} K_{\alpha}$.

Fig. 6. (a) STEM-EDS elemental mapping images of Fe overlapped with Co maps of NdAl-infiltrated sample. The selected analysis peaks for the elemental maps are Fe $K_{\alpha}$, and Co $K_{\alpha}$. (b-d) NBED patterns taken from $\mathrm{Nd}_{2} \mathrm{Fe}_{14} \mathrm{~B}$ phase, interface and intergranular Nd-rich regions, respectively; (e) schematic models of the crystallographic ORs between $\mathrm{Nd}_{2} \mathrm{Fe}_{14} \mathrm{~B}$ phase and the Nd-rich phase; (f) NBED pattern taken from another intergranular Nd-rich grain. 
Fig. 7. (a) STEM-EDS elemental mapping images of Ga overlapped with Al maps of NdAl-infiltrated sample. The selected analysis peaks for the elemental maps are Fe $K_{\alpha}$, and Co $K_{\alpha}$. (b,c) NBED patterns taken from amorphous and $\mathrm{Nd}(\mathrm{Fe}, \mathrm{Al})_{2}$ intergranular Nd-rich regions, respectively; (d) STEM-HAADF image and EDS maps taken from the $\mathrm{Nd}(\mathrm{Fe}, \mathrm{Al})_{2}$ phase. 
Fig. 1

a)

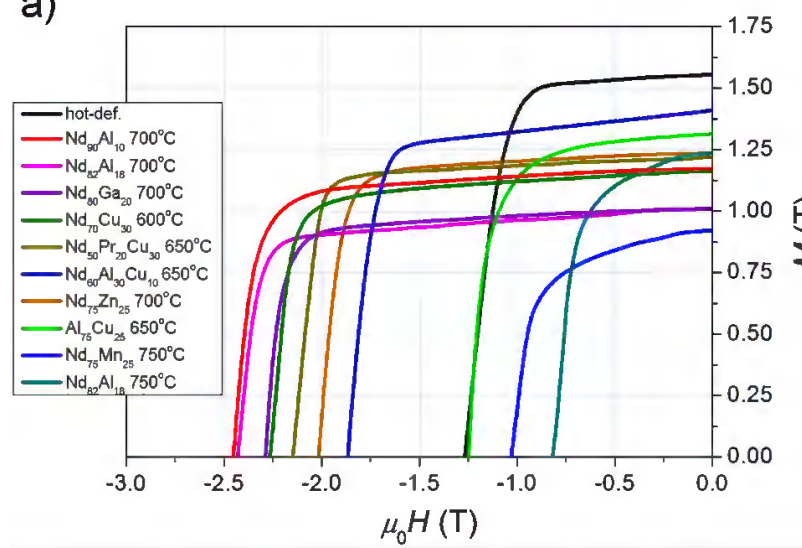

b)

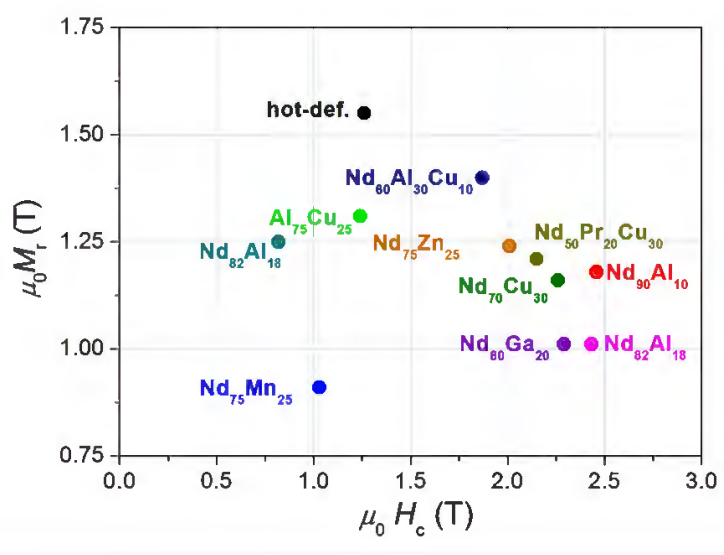


Fig. 2

a)

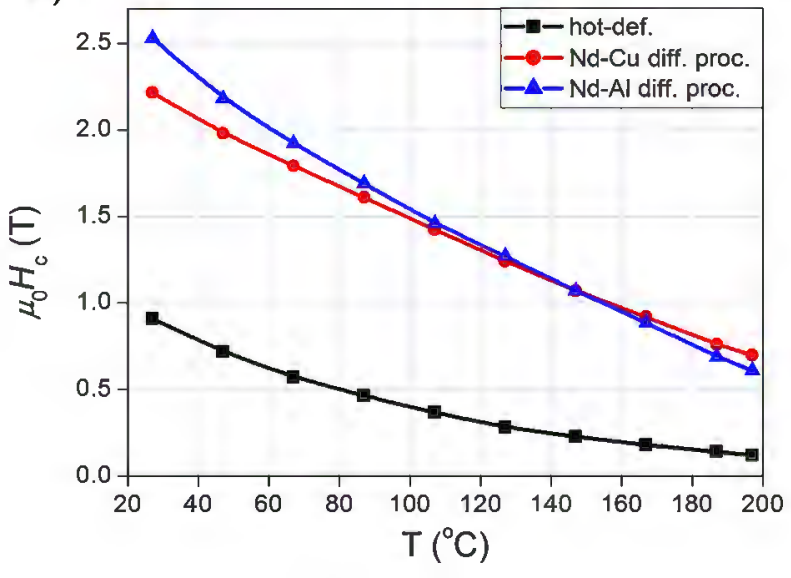

b)

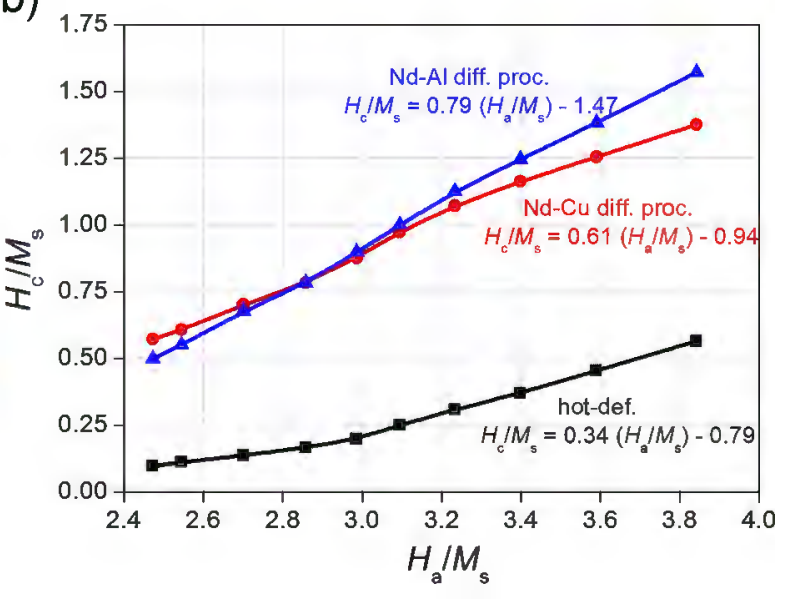


Fig. 3

Hot deformed
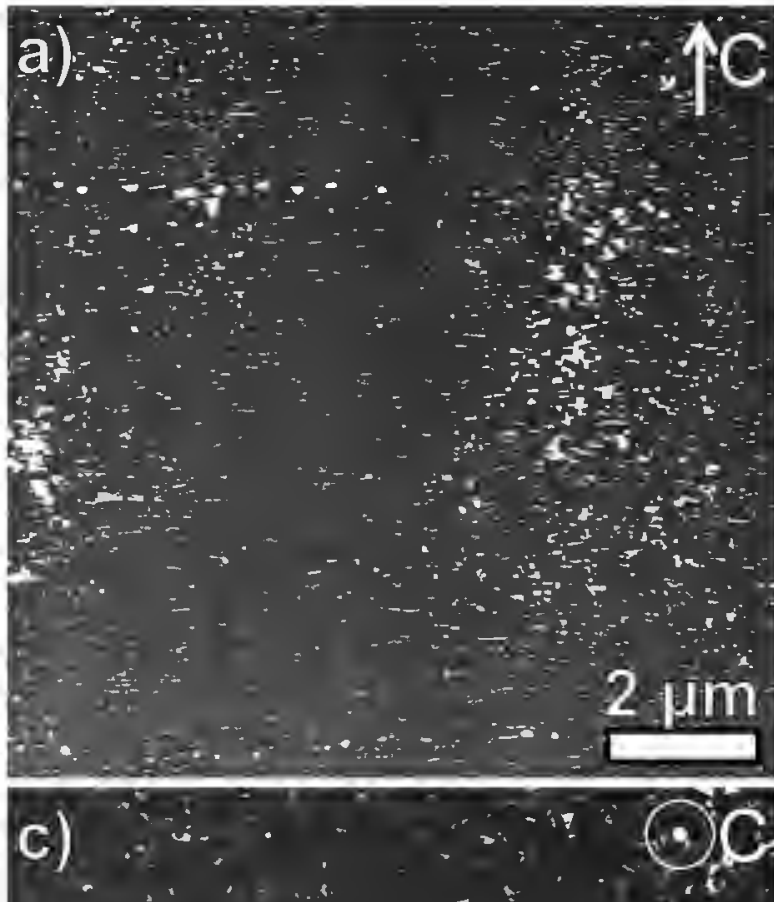

c)

$2 \mu \mathrm{m}$
NdAl-infiltrated
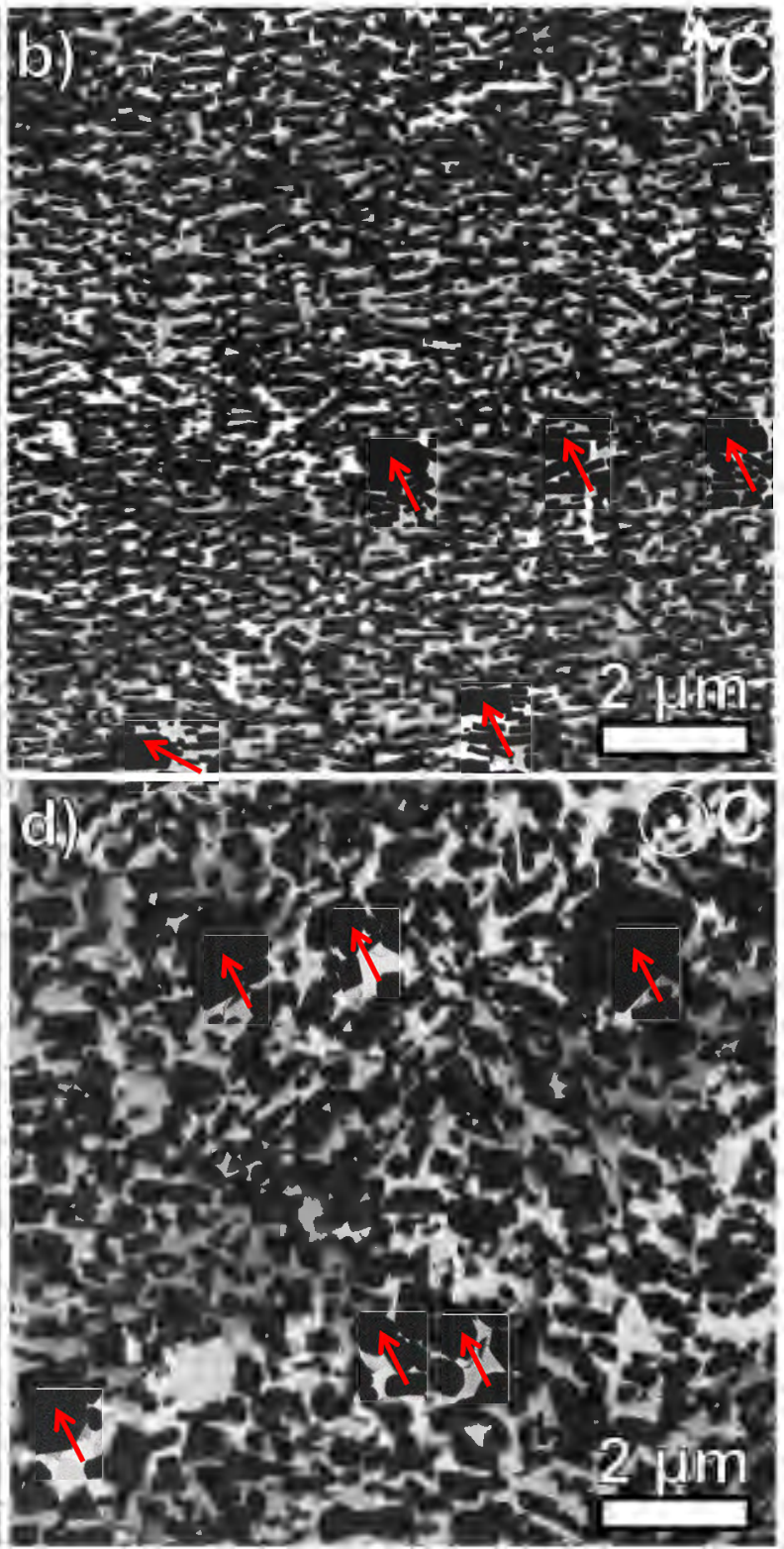
Fig. 4

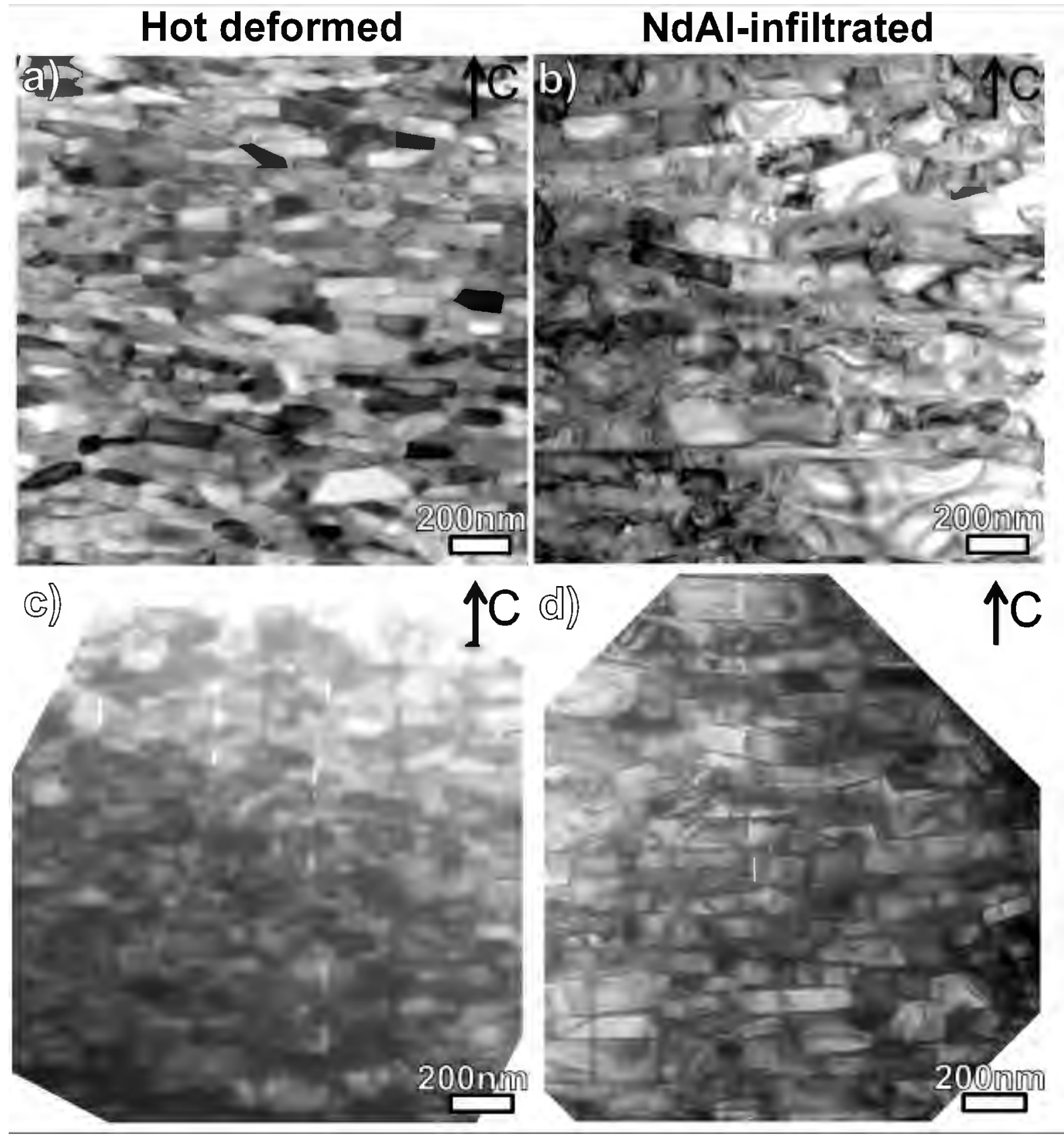


Fig. 5

(a)

(b)
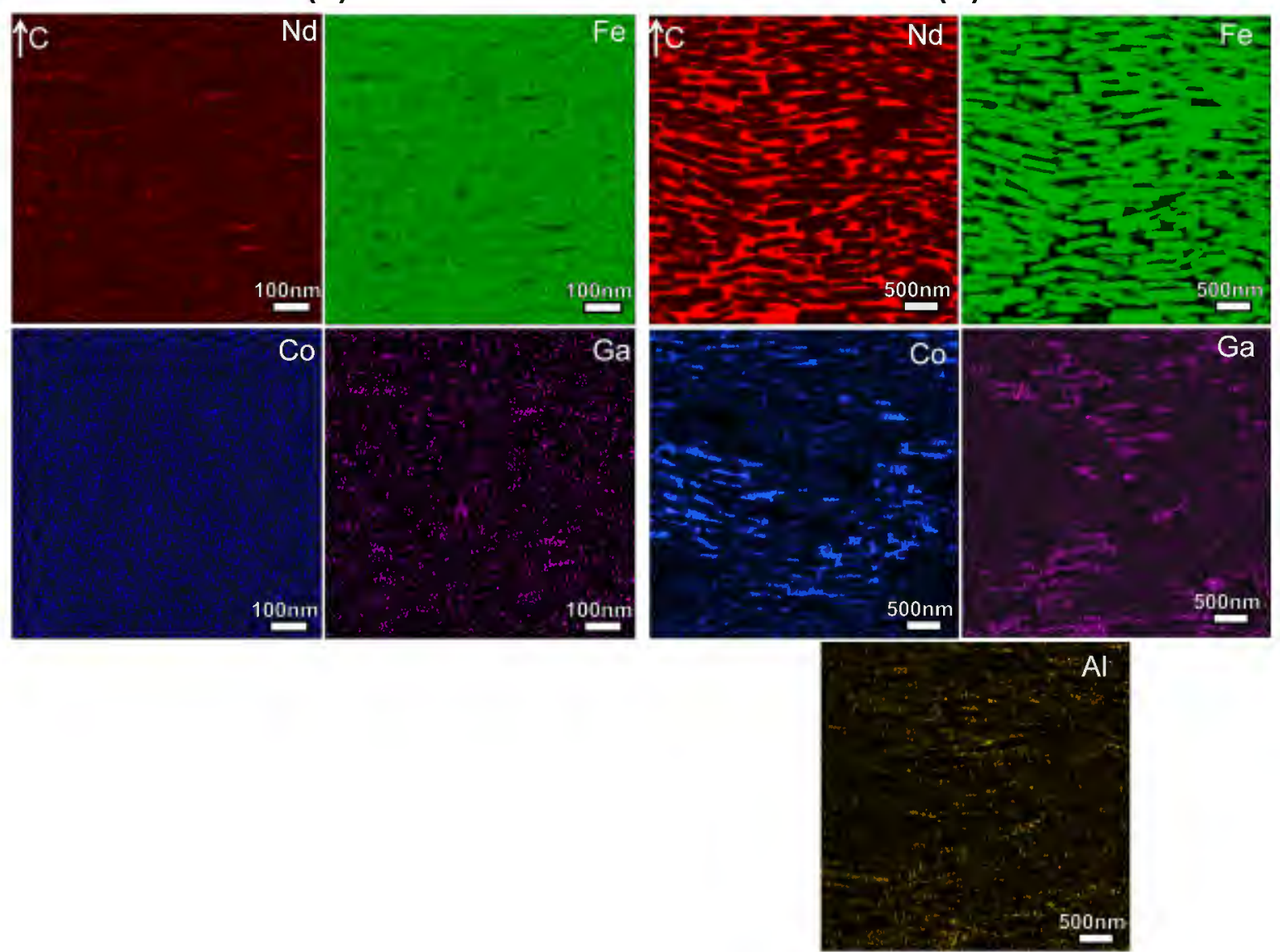
Fig. 6

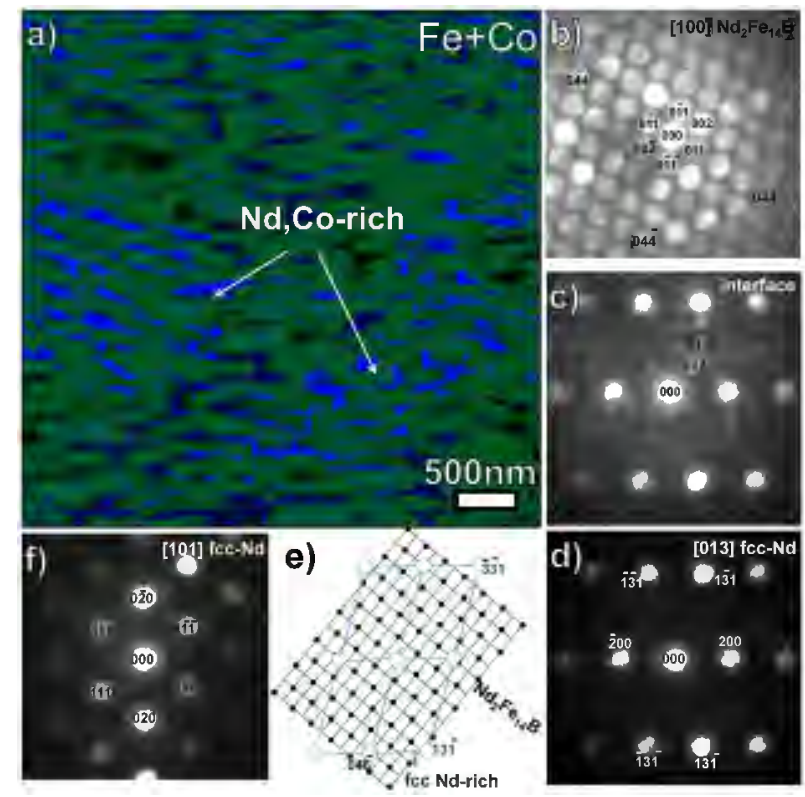


Fig. 7

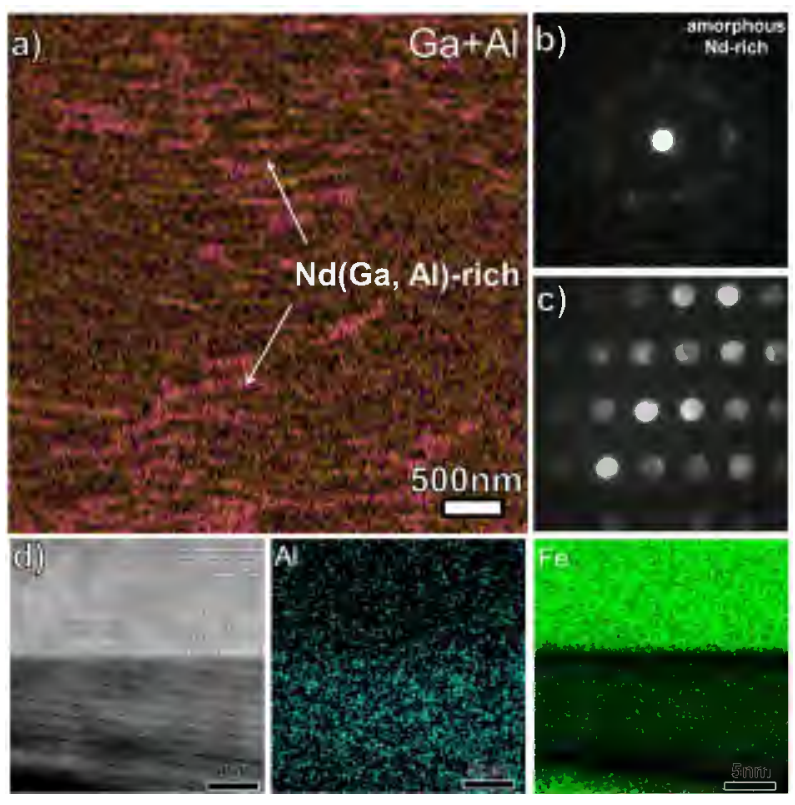

